\title{
Mugimenduzko joskera batzuen oinarri semantikoez: frantsesaren adibidea
}

\author{
Mixel Aurnague Miguelgorry
}

CLLE-ERSS (CNRS - Université Toulouse - Jean Jaurès) \& ILCLI (UPV/EHU)

\section{(On the semantic basis of some motion constructions: the example of French)}

DOI: $10.1387 /$ gogoa.15626

\begin{abstract}
Space and motion being now a rather well studied topic, it is likely to offer an appropriate field for an in-depth analysis of the relations between semantics and syntax. After outlining the theoretical framework used for the definition of motion eventualities (setting out, in particular, the notions of change of placement and change of relation), we examine a specific construction of French in which a change of relation - expressed by an appropriate spatial PP- adds to the semantic content of the verb that basically denotes a simple change of placement. We show that the possibility of integrating a verb in such a construction is greatly conditioned by the semantics of this lexical unit. Four meaning properties seem to govern the construction studied and, after a short review of each of them, we propose to group them under the concept of "tendenciality».
\end{abstract}

Keywords: motion verbs and constructions, semantic content, change of placement, change of relation, tendenciality.

\section{Sarrera: Talmyren tipologiatik frantsesaren datuetara ${ }^{1}$}

Asko dira azken hiru hamarkadetan mugimenduaren adierazpenaz burutuak izan diren azterketak, dela joskera/sintaxia eta semantikaren interfazean

1 Artikulu hau, Aurnague (2011)-ko zenbait datu eta oharretan bermatzen da, argitalpen hartan egin genituen hainbat proposamen aurkeztuz, sakonduz eta hedatuz. 
eginak diren analisi orokorren esparruan, dela espazioaren deskribapena bera helburutzat hartzen duten lanen inguruan. Alor zabal honetan, bada ikerlari anitzen arreta bildu duen joskera bat, hau da «moldezko»/«manerazko» aditz bat eta espaziozko preposizio sintagma (PS) bat elkartuz mugimendu «telikoa» (Vendler 1957) deskribatzen duena $\left((1,3) ; \mathrm{IS}_{\mathrm{kkt}}\right.$ : entitate «kokatua» edo lokalizatua denotatzen duen izena, $\mathrm{IS}_{\mathrm{kktzl}}$ : entitate «kokatzailea» edo lokalizatzailea denotatzen duen izena). Moldezko predikatuak atelikoak dira berez (2) eta joskera horien interesa ahalbidetzen duten «aspektu» aldaketan datza besteak beste (3) (Krifka 1995; Tenny 1995). Barne aspektu edo ekintza eraz ('Aktionsart'-az) gain, inergatibotasun eta inakusatibotasunaren arteko oposizioarekin zerikusteko du aipaturiko joskerak (Levin \& Rappaport 1992, 1995). Moldezko aditz asko inergatiboak izanik, inakusatiboa daitekeen egiturara bihurtzen ditu eta, espaziozko PSren eransketak.

(1) (Det) IS $\mathrm{k}_{\text {kkt }} \mathrm{A}_{\text {mold }} \mathrm{P}_{\text {esp }}$ (Det) IS $\mathrm{S}_{\text {kktzl }}$ [ingelesarentzat]

(2) Max walked for two hours/??in two hours

'Max bi orduz/bi ordu(t)an ibili da'

(3) Max walk into the meadow (in two minutes/??for two minutes)

'Max (bi minutu(t)an/bi minutuz) oinez joan da pentzera'

Oso zabalduak dira engoitik Talmy-ren $(1985,2000)$ analisi argigarrien ildoan garatu diren tipologiak (espazio «dinamikoaren» adierazpenari lotuak). Jatorrizko bereizketari jarraikiz - eta ordutik hona egin zaizkion kritika eta eranskin garrantzitsuak alde batera utziz (adib.: Slobin 2003, 2004) - bi hizkuntza klase nagusi badirela iragartzen du Talmyren ikuspegiak. ${ }^{2}$ Hizkuntza mota batek «sateliteen» bitartez — hau da, adposizio eta partikuleen bitartez- aipatuko luke mugimenduaren 'path' atala edo «joanbidea» ${ }^{3}$ (hortaz, 'satellite-framed' edo «sateliteek egituraturiko» hizkuntzak dira), aditzari legokiokeelarik mugimenduaren moldea edo manera ('manner' atala) zehaztea. Kategoria honetan sartuko lirateke ingelesa eta, orokorrago, germaniar hizkuntzak, baita eslabiar eta finougriar familietako lengoaiak, txinera eta abar. Beste hizkuntza klase batean aditzak du joanbidearen adierazpena bere

2 Geroztik, kategoria gehiago eta berdin continuum oso bat badela uste dute ikerlari frankok, Talmyren bi klaseak honen bi muturretan litezkeelarik.

3 Gauza desberdin asko sartzen ditu Talmyk 'path' kontzeptuaren barnean: lokalizazio mugiezkorra, mugarik gabeko mugimendua ('unbounded path': Jackendoff 1983, 1990), mugimendu mugatua ('bounded path': Jackendoff 1983, 1990). Aditzek egituraturiko vs. sateliteek egituraturiko hizkuntzen arteko diferentziak mugimendu mugatu eta telikoan agertzen direnez gehienbat, 'bounded path' nozioa hobesten dugu eta «joanbide» hitzaren bitartez itzultzen dugu (frantsesez 'trajet' erabilia delarik). Erlazio eta kokapen aldaketez osatuak dira joanbideak (ikus 2. atala) eta «zentzu hertsiko» mugimendu gisa dakuskikegu. Mugarik gabeko higidurak oso desberdinak izanik gure ustez (atelikoak dira eta kokapen aldaketa hutsez osatuak: cf. 2. atala), aparteko trataera eman behar zaiela iduritzen zaigu. «Ibilbide» edo «ibilaldi» hitzen bidez aipa daitezke ('trajectoire' edo 'parcours' frantsesez). 
gain hartzen ('verb-framed' edo «aditzek egituraturiko» hizkuntzak dira) eta perpaus bakunetik at dauden tresnetara jo behar da moldearen deskribatzeko orduan (gerundiozko proposizioak gehituz adibidez). Frantsesaz gain, beste lengoaia franko leudeke multzo honen barnean (familia erromaniar zein semitikokoak, japoniera, koreera, turkiera...). Dikotomia honi zorrozki eutsiz, aditzek egituraturiko hizkuntzek, moldezko aditz bat eta espaziozko PS bat erabiliz mugimendu teliko bat deskriba dezaketen joskerarik ez daukatela ondoriozta daiteke. Honela, ingeleseko (3-4) adibideek entitate kokatzailean (hots, lokalizatzen duen entitatean) bukatzen den higidura aipatzen dutelarik (edo aipa dezaketekarik), frantsesezko esaldi paraleloek (5-6) ez lezakete horrelakorik egin (mugimendu osoak entitate kokatzailean iragan behar $\mathrm{du}$ ). Asko dira, funtsean, ikuspegi zorrotz honi jarraikitzen zaizkion ikerlariak (Vandeloise (2008) barne).

(4) Max skated under the bridge

'Maxek zubi azpi-an/ra patinatu du'

(5) Max a marché dans le pré

'Max pentzean ibili da'

(6) Max a patiné sous le pont

'Maxek zubi azpian patinatu du'

Frantsesaren kasuari erreparatuz, datuak ez direla baieztapen horrekin bat heldu erakutsi nahi du artikulu honek. Beste era batez erranik, badira hizkuntza honetan moldezko aditz bat eta espaziozko PS bat oinarritzat hartuz mugimendu telikoak adieraz dezaketen perpausak (aski zabalduak diren deskribapenak dira gainera). Posibilitate hau gutxitan apuntatua izanik (baina ikus: Fong \& Poulin 1998, Kopecka 2009), datu hutsetatik hara joaten saiatuko gara, interesatzen zaigun joskeraren gibelean diren faktore semantikoak argitan ezarriz. Erabiltzen dugun marko teorikoa laburbildu ondoan (2. atala), aditz mota desberdinen eta heien azpian dauden (adierazko) ezaugarriak azaltzen jardungo dugu (3-5 atalak). 6. eta azken atalean, ordurarte bilduriko datuen egituratzen eta arrazoitzen saiatuko gara.

\section{Marko teorikoaz zenbait hitz: kokapen aldaketa eta erlazio aldaketa}

Hemen aipatuko ditugun lexemak baino zabalagoa da gure lanetan aztertuak diren mugimendu aditzen multzoa eta entitate mugikor baten higidura «autonomoak» denotatzen dituzten aditz irangangaitzez osatua dela erran dezakegu ('transitifs indirects' edo «zeharkako irangankorrak» barne): aller à '-ra joan', arriver 'iritsi, heldu', déraper 'irristatu, lerratu..., irrist egin', descendre 'jaitsi, beheiti joan', entrer 'sartu', foncer 'ziztu bizian ibili/joan', se hisser 'indarrez bere burua igo', partir 'joan, alde egin', ramper 'herrestan/arrastaka, 
narrasean ibili edo joan', se rendre '-ra joan', sortir 'atera, jalgi'... Joskerazko eta semantikazko desberdintasun nabariak agertzen dituzte predikatu hauek beste zenbait mugimendu aditzekin alderatuz gero, eta bereziki eragindako mugimendu bat deskribatzen dituzten espazio predikatu dinamikoen aldean (irangankor «zuzenak» direnak gehienbat): amener 'ekarri, erakarri', apporter '(zerbait) ekarri', conduire 'lagundu, gidatu', emporter 'eraman, eroan', trâेner 'herrestan/arrastaka eraman edo erabili, herrestatu', transporter 'garraiatu, eraman'...

Azken bi hamarkadetan bederen, bereizketa nagusi bat agertzen da mugimenduaren adierazpenaz burutu diren lanetan, higitzeko moldea edo manera adierazten duten aditzak eta «zentzu hertsiko» mugimendua denotatzen dutenak kontrajartzen direlarik (adib.: Jackendoff 1990; Levin 1993; Levin \& Rappaport 1992): foncer 'ziztu bizian ibili/joan', grimper 'atzaparka/apoka igo', marcher (oinez) ibili', zigzaguer 'sigi saga egin edo ibili' vs. arriver 'iritsi, heldu', partir 'joan', sortir 'atera, jalgi', se rendre '-ra joan'. Bereizketa honen sorburuak badu, seguraski, zerikustekorik arestian aipatu dugun molde/manera ('manner') eta joanbidearen ('path'en) artean Talmyk zehazturiko kontrastearekin. Moldea eta zentzu hertsiko mugimenduaren arteko diferentziak tratatzerakoan hizkuntzalari frankok aditzen barne aspektura edo ekintza erara jo dute (adib.: Dini \& Di Tomaso 1999): lehenbiziko nozioak (hots, moldeak) prozesu atelikoak sor litzakeelerik, bigarrenak (zentzu hertsiko mugimenduak) gertakizun telikoei egin liezaieke bide. Holako bereizketaren hurbiltze aspektualak arazo bat baino gehiago sortzen du gure ustez (Aurnague 2012) eta espazio-denborazko kontzeptuen bitartez azaldu behar daitekeela iduritzen zaigu, barne aspektuarekiko lotura bigarren urrats batean zehaztuz.

Bizkitartean, espazio-denborazko kontzeptu egokiak behar bezala argitan jartzea ez da, inondik ere, lan erraza, «leku aldaketa» ('changement de lieu': Laur 1991; 'change of location/place': Randall 2010) edota «berezko mugimendu norabidetua»n ('inherently directed motion': Levin 1993) oinarrituriko sailkapenek erakusten duten moduan. Lehenbiziko nozioak «lekuak» ez diren entitateak leku gisa kategorizatzen edo sailkatzen dituen bitartean (espazio erlazio mugiezkorrak inklusio geometriko hutsera murriztuaz gain: Aurnague \& Vieu 2015), bigarrenak zentzu hertsiko mugimendu aditzen berezitasuna ez den irizpidea erabiltzen $\mathrm{du}^{4}$ (Aurnague 2011). Zaila izanagatik, mugimenduzko aditz eta prozesuen espazio-denborazko definizio egoki bat eratzea guztiz posible dela deritzogu. Bi nozio garrantzitsu behar lituzke konbokatu honelako definizio batek, hau da kokapen aldaketa eta oinarrizko espazio-erlazio aldaketa. Entitate kokatu batek (hots, lokalizatua den enti-

\footnotetext{
${ }^{4}$ Molde edo manerazko zenbait aditzek ezaugarri hau dakarte beren semantikan (ikus 4. atala). Hori baino gehiago, mugimendu hertsiko predikatu gutik dute egiazko norabide bat denotatzen. Antzeman daitekeenez, bi kontzeptu desberdin nahasten dira analisi askotan: norabidea eta erlazio aldaketa (ikus urrunago).
} 
tate batek) kokapen aldaketa batean parte hartzen du, baldin eta lurrak definitzen duen erreferentzia markoan bere posizioa aldatzen bada prozesua iragan arau (kokapen aldaketari «translokazioa» deitzen zaio beste lan batzuetan) —s'asseoir-ek 'eseri, jarri' ez bezala, posizio aldaketa bat eskatzen du marcher-k '(oinez) ibili' inguruneko erreferentzia markoaren baitan. Bestalde, J.P. Boons-i (1987) zor diogun oinarrizko espazio-erlazio aldaketak, entitate kokatu eta kokatzailearen arteko erlazio lokatiboa prozesuaren ondorioz aldatzen dela berekin ekartzen du —Max a marché dans la prairie 'Max pentzean ibili da' eta Max est entré dans la prairie 'Max pentzean sartu da' esaldien arteko aldea bigarrenak pentzearekiko suposatzen duen erlazio aldaketan datza preseski (être dans).

Argitan ezarririko bi kontzeptuek konbinaketa konplexu batera garamatzate, zeinetatik lau aditz eta prozesu klase xedatu baitaitezke (Aurnague 2011, 2012). Gorago aipagai izan ditugun erlazio aldaketarik gabeko kokapen aldaketek (gogora marcher-en adibidea), moldezko edo manerazko (mugimendu) aditzak barnean hartzen dituzte bereziki. Alderantziz, oinarrizko espazio-erlazio aldaketa bat kokapen aldaketarik gabe gerta daiteke, euste/ kontaktuzko erlazioan (être sur) oinarrituriko zenbait predikatuk erakusten duten bezala (adib.: se poser 'pausatu') (Aurnague 2011). Gure marko teorikoaren muinean dauden zentzu hertsizko aditzek, berriz, erlazio aldaketa bat eta kokapen aldaketa bat uztartzen dituzte. Badira, azkenik, bi nozio horietatik bakar bat ere hartzen ez duten aditz eta prozesuak: hortan sar daitezke, besteak beste, postura aldaketa huts bat deskribatzen dituzten predikatuak (adib.: s'accroupir 'kukubilkatu, kokorikotu', s'asseoir 'eseri, jarri', se recroqueviller 'kuzkurtu, uzkurtu, kiribildu') eta entitate kokatuak entitate kokatzailean egoteko duen moldea zehazten dituztenak (adib.: se blottir 'kurubilkatu, uzkurtu', se cacher 'ezkutu, gorde', s'embourber 'lokaztu', se ficher 'sartu, landatu, finkatu').

Finkaturiko kategorietatik hara, erlazio aldaketen eta kokapen aldaketen arteko interakzioak, bi kontzeptu horiek biltzen dituzten predikatuen bidez aztertu behar dira, erran nahi baita zentzu hertsiko mugimendua adierazten duten predikatuei begiratuz. Aditz horien semantikak (aller + Prep '-ra joan', arriver 'iritsi, heldu', partir 'joan', sortir 'atera, jalgi', se rendre '-ra joan'), bi espazio-denborazko eskema nagusi azaleratzen ditu (Aurnague 2011). Alde batetik, erlazio aldaketak eta kokapen aldaketak denboran bat egiten duten egitura bat osa dezakete. Konfigurazio honen adierazle ditugu, adibidez, entrer 'sartu' eta sortir 'atera, jalgi' aditzak, heien azpian dagoen être dans espazio erlazioari (edo, zehatzago, erlazio horren gainean eraikia den aldaketari) kokapen aldaketa konkomitante bat gehitzen baitzaio. Bestaldetik, denboran bereizita gerta daitezke bi aldaketak (erlaziozkoa eta kokapenezkoa), entitate kokatzailearekiko erlazio aldaketak kokapen aldaketa bat lukeelarik aurretik (adib.: aller à, se rendre '-ra joan'). Mugimendu hertsiko aditz bakoitzari «polaritate» bat eman dakioke, oinarrian duen erlazio aldaketaren arabera: ha- 
sierako polaritateak erlazioa lehenik baieztatua dela suposatzen du, eta ondotik ezeztatua (informazio «positiboa» aurretik doa: $\mathrm{r} \cdots \triangleright \neg \mathrm{r}$; adib.: sortir, être-dans $\cdots \triangleright \neg$ être-dans), bukaerako polaritateak eredu simetrikoa agertzen duela (informazio «positiboa» bigarrenez/atzetik doa: $\neg \mathrm{r} \cdots \triangleright \mathrm{r}$; ex. : entrer, $\neg$ être-dans $\cdots \triangleright$ être-dans). Era berean, «bitarteko polaritateaz» mintzo daiteke baldin eta espazio erlazioaren baieztapena aurreko zein ondoko ezeztapenez lagundua bada $(\neg \mathrm{r} \cdots \triangleright \mathrm{r} \cdots \triangleright \neg \mathrm{r})$. Halere, oso guti dira eredu honetan oinarrituak diren frantsesaren aditz eta aditz lokuzioak (adib.: couper par '-tik joan edo hartu', passer par '-tik igaro edo iragan').

(Aurnague 2011)-n xedatu ditugun mugimendu hertsiko zortzi klaseetatik, lexema eta joskera gehien biltzen duena gainean aipaturiko bigarren espazio-denborazko eskeman eratua da. Mugimendu bat aurretik duten bukaerako erlazio aldaketen klasea dugu hau ('final changes of relation with integrated prior motion') eta, honen zehazterakoan, aller à '-ra joan', se rendre '-ra joan', accourir 'lasterka etorri' edo berdin venir 'etorri, jin, jaugin' bezalako aditzak aipa genitzake, baita hizkuntz erregistro apalagoko/laxoagoko s'abouler 'etorri, jin, jaugin', s'amener 'etorri, jin, jaugin' edo rappliquer 'etorri, itzuli'. Lan honetan aztertuak diren joskerek espazio-denborazko eskema berbera dakarte (onartzen dituzten bi interpretazioetatik batean), kokapen aldaketa bat iragaiten baita bukaerako erlazio aldaketa gertatu aurretik.

\section{Abiadura eta indar baten aurkako jarduna}

Lekuzko PS batekin, erlazio eta kokapen aldaketa bat adieraz dezaketen lehen motako aditzek, mugimenduaren abiadurari (eta, zehatzago, abiadura bizkorrari) egiten diote erreferentzia. Courir 'laster egin, lasterka ibili/joan', galoper 'arrapaladan edo lauhazka ibili/joan, lauhazkatu' eta agian trotter 'trostan ibili/joan, lasterka ibili/joan', nola foncer 'ziztu bizian ibili/joan' eta filer 'ziztu bizian ibili/joan; airatu' dira kategoria honetako aditzen ordezkari nagusiak. Usaian onartzen den bezala, azterturiko perpausen bi interpretazioak, PSren funtzio sintaktiko desberdinetan oinarrituak dira, elementu hau modifikatzaile soil (perpausaren edo aditz sintagmaren adjuntua; kokapen aldaketa) edo aditzaren zinezko osagarria (erlazio eta kokapen aldaketa) den arabera (ikus 6. atala).

(7) Max a couru/galopé/(?)trotté à la cuisine 'Max(ek) sukalde-an/ra laster egin du/arrapaladan ibili, joan da/trostan ibili, joan da'

(8) Max a foncé/filé dans le couloir

'Max korridore-an/ra ziztu bizian ibili/joan da'

Bigarren multzo batean, ramper 'herrestan/arrastaka/narrasean ibili edo joan, herrestatu' eta se traîner 'herrestan/arrastaka/narrasean ibili edo joan, 
nekez ibili' bezalako aditzak aurkitzen ditugu, kokapen aldaketa batek ahalegin berezi bat eskatzen duela jakitera ematen dutenak (gizakientzat bederen). Honelako ahaleginak, mugimenduaren gauzatzea galarazten eta zailtzen diharduten «indar» batzuen gainditzea du helburu —indarrok entitate kokatuan berean edo haren ingurumenean sor daitezkeelarik ${ }^{5}$. Lehenagoko moduan, aditz hauek (bukaerazko) PS egokiekin josiz gero interpretazio bikoitza bidera dezakete, bietatik batek erlazio eta kokapen aldaketa bat berarekin baitakar (besteak, aldiz, kokapen aldaketa soil bat):

(9) Max a rampé sur la terrasse

'Max terraza-n/ra herrestan/arrastaka/narrasean ibili, joan da'

(10) Max s'est traîné au salon

'Max saloi-an/ra herrestan/arrastaka/narrasean ibili, joan da'

\section{Norabidea}

Norabidea adierazten duten kokapen aldaketazko predikatuek hirugarren aditz multzo bat osatzen dute, espaziozko PS batekin erlazio eta kokapen aldaketa bat aipa dezaketenak: avancer 'aurreratu, aitzinatu, aurrera/aitzina egin edo joan', dégringoler 'itzulipurdika edo ziztuan jaitsi', dévaler 'itzulipurdika edo ziztuan jaitsi', grimper 'atzaparka/apoka igo', se hisser 'indarrez bere burua igo', monter 'igo, goiti joan', reculer 'atzeratu, gibelatu, atzera/gibel(era) egin edo joan'... Aurnague (2011)-n iradoki bezala, aditz hauek kokapen aldaketa bat dute, oroz gainetik, deskribatzen (hau da, norabide jakin batean gertatzen den mugimendua, berez muga jakinik ez duenak: gure analisiak Sarda-ren (1999) proposamenekin bat egiten du puntu honetan). (11-12) perpausetan funtzionamendu hau argiki antzeman daiteke, PSk denotzen duen entitate kokatzailearekiko erlazio aldaketarik ez baitute, inolaz ere, inplikatzen. Datu diakronikoek (13-14) kokapen aldaketazko aditzen multzoko kidetza hau baieztatzen dute, gaur egungo norabide aditz asko bezala (adib.: avancer, reculer, dévaler, dégringoler, grimper), avoir 'edun' aditz laguntzailearekin maiz agertzen baitziren antzinako garaietan monter 'igo, goiti joan' eta descendre 'jaitsi, beheiti joan' — joera honek 20. mende erditsu arte iraun duelarik. ${ }^{6}$ Gai honen harian, gauza garrantzitsu bat oroitarazi behar da: kokapen aldaketei murriztua izan gabe, avoir 'edun' aditz laguntzailearen erabilpena biziki zabaldua dirudi mota honetako predikatuen artean eta, Le-

\footnotetext{
5 Igurzketak, mugimenduan aritzen diren gorputz parteen indar erlatiboa gorputzaren gainerako atalen pisu/inertziarekin alderatuz.

${ }^{6}$ Horra beste bi adibide: Le tas des ouvriers a monté dans la rue, et ces maudits s'en vont... 'Langile(en) mordoa igo da kalean, eta madarikatu horiek badoaz...' (A. Rimbaud, Le Forgeron, 1870); Il a monté encore, un peu plus avant dans le bois 'Areago igo da, basoan barna(go)' (M. Genevoix, Le Lac fou, 1942).
} 
vin \& Rappaport $(1992,1995)$ jarraikiz, inergatibotasunaren ondorio edo seinale gisa ikus daiteke.

(11) L'expédition a avancé à travers la forêt 'Espedizioa(k) oihanean barna aurrera egin du/aurreratu da'

(12) Le chamois a dévalé/est descendu le long du ravin 'Orkatza amildegian zehar (itzulipurdika edo ziztuan) jaitsi da'

(13) La terre qui a monté autour de ses murs, les débris dont on l'a encombré, en font une crypte étroite resserrée, nauséabonde... (M. du Camp, Le Nil, Egypte et Nubie, 1854)

'Bere pareten inguruan igo den lurrak, trabatu duten hondarrek, kripta hertsi estua bilakatzen dute, higuingarria'

(14) Monsieur votre argentier a descendu comme un chat le long des murs $(\mathrm{H}$. de Balzac, Maître Cornelius, 1846)

'Zure diruzain jauna gatu bat bezala jaitsi da pareten ertzetik'

Monter eta descendre ardatz dituzten 19. mendeko beste zenbait adibidek (15-16), avoir aditz laguntzaileaz eta espaziozko PS egokiaz osaturiko bi predikatu hauen erabilpenek, erlazio eta kokapen aldaketa bat adieraz zezaketela erakustera ematen dute (beste adibide batzuk eskuragarriak dira, a descendu de la voiture 'autotik jaitsi da' formaren gainean eratuak direnak kasu). Haatik, norabide predikatuak être aditz laguntzailearekin agertzen diren joskeren hedatze goiztiarra mota honetako esaldiei egotz lekieke, erlazio eta kokapen aldaketa bat argiro deskribatzen baitute (inakusatiboarekiko lotura ikus 1. atalean). Dena dela, eta ikuspegi sinkroniko eta zentralago bat hartuz, gaur egungo norabide aditzek kokapen aldaketa bat zein erlazio eta kokapen aldaketa bat denota dezaketela erran daiteke - espaziozko PS batekin joanez gero, aditz laguntzailea edozein gisatakoa izanik: (17-18), (11-12)rekin alderatu. ${ }^{7}$

(15) ...il a monté jusqu'au gros chêne (G. Sand, Les Maîtres sonneurs, 1865) '...haritz handiraino igo da'

(16) ...la peinture de son visage a descendu sur la pourpre (G. Flaubert, La Tentation de Saint-Antoine, 1849)

'... bere aurpegiko tindua purpuraraino jaitsi da'

(17) Max a avancé dans le couloir

'Max korridore-an/ra aurreratu da'

\footnotetext{
7 Bi aditz laguntzaileak oraino onargarriak direlarik (adib.: ( $\left.s^{\prime}\right)$ avancer, (se) reculer), être-n gainean eraturiko erabilpenak aurreratze hutsa nekezago adieraz lezakeela iduri du, avoir-en gainean eraturikoarekin erkatuz: (?)L'expédition s'est avancée (= a progressê) à travers la forêt 'Espedizioa(k) oihanean barna aurrera egin du/aurreratu da'; (11)rekin alderatu). Alderantziz, bigarren motako egiturari entitate kokatuarekiko erlazio eta kokapen aldaketa bat deskribatzea zailago zaio (interakzio kanonikoa (Andersson 2007; Vandeloise 1986)): Max (?)a avancé/s'est avancé devant le maire 'Max alkatearen parera aurreratu da'.
} 
(18) Le chamois a dévalé/est descendu dans le ravin

'Orkatza amildegi-an/ra (itzulipurdika edo ziztuan) jaitsi da'

Erlazio eta kokapen aldaketa bat lekarketen joskeretan agertzeko posibilitatea predikatuen norabidezko adierari hertsiki lotua izanik ere, arakatze zehatzago batek alde txikiak erakusten ditu aditz horien artean, kontestua eta munduari buruzko ezagutzaren papera argitan jartzen dutenak (aipatzen diren mugimenduen «mugatzeko» orduan). Zehaztasunetan sartu gabe, monter 'igo, goiti joan' eta descendre 'jaitsi, beheiti joan' être 'izan' aditz laguntzailearekin joateko duten joera berezia — gaur egun bederen- mugimendu bertikaletan usu agertzen diren entitate kokatzaileen ondorio dela baiezta daiteke, entitate kokatuaren higidurari mugak jar liezazkiokeelako horrek (adib.: lurra/(lur)zorua, solairuak (eraikinak, «entitate mistoak»), zuhaitzak, ibilgailuak eta beste motatako objektuak). ${ }^{8}$ Gisa berean, eta abiadura edo indar baten aurkako jarduna adierazten duten predikatuak ez bezala, norabidezko zenbait aditz «hasierako»SP batekin uztar daitezke («bukaerako»SP batekilako erabilpenaz gain) baina, berriz ere, kontestuak eta munduari buruzko ezagutzak dituzte joskera horiek baldintzatzen. Honela, goranzko mugimendu baten hasiera puntuari erreferentzia egitea (adib.: ?(?)Max est monté du rez-de-chaussée/de la cuisine 'Max behereko solairutik/sukaldetik igo da'; ?(?)Max est monté/s'est hissé/a grimpé du tabouret 'Max aulkitxotik (indarrez/ atzaparka) igo da') beranzko higidura baten hasierako entitatea izendatzea baino baldintzatuagoa dirudi: Max est descendu du premier étage/de la salle de réunion 'Max lehen solairutik/bilkura gelatik jaitsi da', Max est descendu/a dégringolé de l'échelle 'Max zurubiatik (itzulipurdika edo ziztuan) jaitsi da' ${ }^{9}$ Funtsean, egoera multzo murritz batek ditu lehen motako deskribapenak argiki onartzen: Max est (?)monté/remonté de la cave 'Max sototik igo/berriz igo da'; Une fumée est montée de la vallée 'Ke zerbait ibarretik igo/altxatu da'.

Jadanik igar zitekeenez, mugimenduaren norabidea adierazten duten zenbait predikatuk elementu hau abiadurarekin lotzen dute (adib.: débouler/ dégringoler 'itzulipurdika edo ziztuan jaitsi', dévaler 'itzulipurdika edo ziztuan jaitsi') edota indar baten aurkako jardunarekin (adib.: grimper 'atzaparka/ apoka igo', se hisser 'indarrez bere burua igo'). Dégringoler eta dévaler-ren intentziorik gabeko erabilpenek ere indarra(k) inplikatzen d(it)u(z)te baina, aldi honetan, modu desberdinez diharduen nozioa da, entitate kokatua mugimenduan jartzen baitu (haren higidura oztopatu baino).

\footnotetext{
8 Ildo beretik, aurrerantzeko mugimenduek ((s')avancer 'aurreratu, aitzinatu, aurrera/aitzina egin edo joan') entitate kokatzaile bat erreferente gisa maizago hartzen dutela dirudi, atzerantzeko mugimenduek baino ((se) reculer 'atzeratu, gibelatu, atzera/gibel(era) egin edo joan'). Hortik dator, seguraski, avancer-k être aditz laguntzailearekin usu(ago) agertzeko duen joera.

9 Disimetria honen azpian, arrazoi franko sinplea daiteke, gure ustez, hau da gizakiek lurzoruan edo lurzoruaren gainean egoteko duten usaia, entitate kokatzaile hau mugimendu askoren abiapuntu zehaztugabea bihurtzen delarik.
} 


\section{Indar batek eraginiko mugimendua}

Indar batek eraginiko mugimendua da, preseski, argitan ezarri dugun laugarren eta azken tasuna, kokapen aldaketa batetik erlazio eta kokapen aldaketarako bihurtzea baldintza dezaketen ezaugarrien artean. Kontzeptu hau, couler 'erion, jario, isuri', dégouliner 'isuri', déraper 'irristatu, lerratu..., irrist egin', glisser 'irristatu, lerratu..., irrist egin' edo rouler 'errodatu, pirritatu, pirritan ibili edo joan' bezalako aditzen oinarrian dago, indar batek edo gehiagok — batez ere entitate kokatuaz kanpokoek - higidura eragiten dutela adierazia delarik. Kanpoko indar hauek (grabitatea, bultzadak, oztopoak, eta abar), entitate kokatu geldi edo mugikorraren barneko beste zenbait ezaugarrirekin batera (forma edo trinkotasuna, oldarra, eta abar), azken honen (hasierako) «oreka» hausten dute eta nahigabeko mugimendura erakartzen. Hemen darabilgun oreka nozioa (entitate geldi edo mugikor batena) eta, oro har, indarrei emana zaien papera, L. Talmyren (2000) «indarren dinamika»tik hara doala ohartarazi behar da. Arrazoi horrengatik dugu berak proposaturiko terminologia albo batera uzten (agonista/antagonista oposizioa bereziki). Indar batek eraginiko mugimenduaz gain, nolabaiteko higiduraren linealtasuna dakar arakatuak diren aditzen semantikak («mugimendu lineal orientatua») eta horrek Talmyren hipotesietatik bat indartzen duela iduritzen zaigu, zeinaren arabera hizkuntzetan kodeturiko indarrek linealki jarduten baitute.

Aurreko kasuetan bezala, entitate kokatuaz kanpoko indar batek eraginiko mugimenduak erlazio eta kokapen aldaketa batean oinarrituriko interpretazioari egiten dio bide, perpauseko aditza ezpaziozko SP egoki batekin konbinatuz gero (19-22). Gainera, eta kanpoko indar honek (edo hauek) aurreko oreka bat hausten du(t)en heinean, predikatu hauetatik zenbait «hasierako» entitate kokatu bat izendatzen duen PSrekin ager daitezke: La peinture a coulé/dégouliné du mur 'Tindua paretatik isuri da'; Max a glissé de la corniche 'Maxek erlaitzetik lerratu/irristatu da'.

(19) La peinture a coulé/dégouliné sur le carrelage

'Tindua lauzadura-n/ra isuri da'

(20) Max a glissé dans le ravin

'Max amildegi-an/ra lerratu/irristatu da'

(21) La voiture a dérapé sur le bas-côté

'Autoa bide-bazterre-an/ra lerratu/irristatu da'

(22) La balle a roulé sur le sol

'Pilota lurre-an/ra pirripitan edo itzulika ibili/joan da'

Indar batek eraginiko mugimenduak argitzen du, halaber, nolaz oreka galtze soilari erreferentzia egiten dioten zenbait aditzek — hala nola basculer 'erori, jausi, uzkaili' edo tomber 'erori, jausi' - erlazio eta kokapen aldaketa bat deskriba dezaketen, bi nozio horiek beren osagai semantikoetan egon ez 
arren (alde horretatik postura aditzen pareko lirateke preditu hauek). ${ }^{10}$ Interpretazio bikoitza sortzen da hemen ere (23-24) eta erlazio eta kokapen aldaketa bat adierazten duenak egoera berezi bat eskatzen duela erraz ikus daiteke: gertakizunaren ondotik, entitate kokatua, eusten dion eremu/azal berri batean aurkitu behar dela hain zuzen ere (hortaz entitate kokatzaile aldaketa bat dago).

(23) Le container a basculé sur le quai

'Edukiontzia kai-an/ra erori/uzkali da'

(24) Max est tombé dans la cour

'Max patio-an/ra erori da'

\section{Ondorioak: «jaiduratasuna» eta mugimendu hertsiaren adierazpena}

Dakusagunez, lau dira kokapen aldaketazko predikatuak erlazio eta aldaketa baten adieraztera ahabilde ditzaketen ezaugarri semantikoak, espaziozko PS egoki batekin elkartuz gero: mugimenduaren abiadura, indar baten aurkako jarduna (intentzionala edo nahitakoa), norabidea (mugimendu lineal orientatua) eta indar batek eraginiko mugimendua. Jadanik azpimarratu bezala, ezaugarri (horietatik) bat baino gehiago har ditzakete beren baitan arakatu ditugun kokapen aldaketazko predikatuek. Le nouveau Petit Robert hiztegiak filer aditzarentzat eskaintzen dituen definizioek alderdi interesgarri hau argitzen eta sakontzen laguntzen dute. Dagokion sartzeari begiratuz, predikatu honen esanahi batek mugimendu lineal orientatua eta indar batek eraginiko higidura batzen dituela ohartzen zaio («(Prendre la forme d'un fil). Couler lentement sans que les gouttes se séparent» '(Hari baten forma hartu). Poliki isuri/jario tantak bereizi gabe') eta beste batek, aldiz, norabidea eta abiadura («Aller droit devant soi, en ligne droite ; aller vite» 'zuzen (aurrera) joan, lerro zuzenean; bizkor edo fite joan’).

Lau ezaugarri edo tasun horiek zerbaitek elkartzen ditu, hau da helburua iradokitzen dutela —edo mugimenduaren jaidura/«jaiduratasuna»—, deskribatzen dituzten higidurak helburu edo (entitate) kokatzaile jakin bati buruz joateko jaidura izan dezaketelako. Intuizio horren gauzatzerakoan, agerian jarri ditugun lau ezaugarriek «familia antzekotasun» bat osatzen dutela aintzakotzat hartuko dugu, jaidura edo «jaiduratasuna» nozioaren azpian da-

\footnotetext{
${ }^{10}$ Kontzeptu horiekin lotura izpirik ez duten beste predikatu batzuk ere, erlazio eta kokapen aldaketazko esaldien iturri izan daitezke: s'abriter 'aterpetu, gerizatu', se cacher 'ezkutatu, gorde', s'embusquer 'ezkutatu, gorde'... Haatik, esaldi horien interpretazioak pragmatikazko jakintzen gainean eraikiak direla dirudi (eta ez jakintza lexikalean, aurreko adibideetan bezala). Erlazio aldaketa soil bat dakarten zenbait predikatuk ere erlazio eta kokapen aldaketa bat adieraz dezakete, hala nola sauter/bondir 'jauzi egin, jauzi'.
} 
goena. L. Wittgensteinek (1953) definituriko tresna teorikoa izanik ere, ez ditugu «familia antzekotasunak» jatorrizko eran erabiltzen hemen baizik eta C. Vandeloisek (1986) proposaturiko moldean, zeinetan (antzekotasunaren) ezaugarri edo tasun bat baino gehiagok batera jardun baitezakete. 1. Irudian laburbilduak dira orain arte aipatuak izan diren zenbait aditzen eduki semantikoa, jaiduratasunaren tasun bakarraz edo berdin sortaz osatuak direnak (zenbait ezaugarri nekez batera daitezke —indar baten aurkako jarduna (higidura intentzionala) eta indar batek eraginiko mugimendua (intentziorik gabekoa), adibidez; hortaz ez daitezke, printzipioz, hiru ezaugarriz gora elkarrekin joan).

\section{Jaiduratasuna}

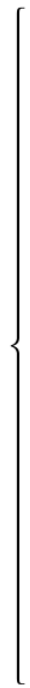

(i) Abiadura (bizkorra)

(ii) Indar baten aurkako jarduna

(iii) Norabidea, mugimendu lineal orientatua

(iv) Indar batek eraginiko mugimendua
Adib.:

courir 'laster egin, lasterka ibili/ joan' (i)

ramper 'herrestan/arrastaka/ narrasean ibili edo joan, herrestatu' (ii)

avancer'aurreratu, aitzinatu, aurrera/aitzina ibili edo joan' (iii)

couler 'erion, jario, isuri' (iv) grimper 'atzaparka/apoka igo' (ii, iii)

dégringoler 'itzulipurdika edo ziztuan jaitsi' (i, iii (, iv))

\section{Irudia}

Jaiduratasuna kokapen aldaketazko predikatu baten parte izateaz gain, azken honek joskera berezietan joan behar duela behin eta berriz azpimarratu dugu, erlazio eta kokapen aldaketa bat deskribatu nahi bada behintzat, erran nahi baita «zentzu hertsiko» mugimendu bat (espaziozko PS egoki bat joskera horien elementu garrantzitsua delarik). Hala eta guztiz, agerian jarri dugun nozio semantiko konplexua da interpretazio dinamiko horien giltzarria. Hatsarrean erran dugunez (ikus 1. atala), eta tipologiazko azterketa gehienek iragarritakoaren kontra, pentsatu baino askoz gehiago dira beraz, frantsesez, erlazio eta kokapen aldaketetara molda daitezkeen kokapen aldaketazko predikatuak. A. Kopeckak (2009) corpusetan atzemandakoarekin bat heldu da gure analisia eta datuen oinarri semantikoei hurbilagotik begiratuz, fenomeno horren nondik norakoen ulertzera ahalbidetzen gaitu. 
'Verb-framed' «aditzek egituraturiko» eta 'satellite-framed' «sateliteek egituraturiko» hizkuntzen arteko kontrastea ez datza, hortaz, interesatzen zaizkigun joskeren ez egotean vs. egotean, baizik eta heien eratze baldintzatuan vs. ez (hain) baldintzatuan. Ingelesa eta beste sateliteek egituraturiko hizkuntzek ez bezala, frantsesak (eta, seguraski, aditzek egituraturiko beste hizkuntza batzuek) alor ezin hobea eskaintzen digu(te) baldintzapen semantiko horren atzean dagoen jaidura edo jaiduratasun nozioa xeheki ikertzeko. ${ }^{11}$

Hastapeneko adibideetara itzuliz, errazki azal daiteke, orain, zergatik (5) bezalako esaldi batek ezin duen erlazio eta kokapenezko gertakizunik deskribatu: jaiduratasuna osatzen duten ezaugarrietatik bakar bat ere ez denez marcher-ren ('ibili'-ren) semantikan aurkitzen, kokapen aldaketa hutsaren adieraztera behartua da perpausa, (aditzari) espaziozko PS bat erantsi arren (mugimendu osoa entitate kokatzailearen barnean iragaiten da). Oso alde txikiko diferentzien ulertzera ere eramaten gaituzte argitan jarri ditugun noziek. Honela, voler 'hegan/hegaz egin, hegaldatu' predikatua kokapen aldaketa soilaren deskribapenari murriztua da frantsesez (marcher bezala), ez baitu iduriz jaiduratasunaren tasunik hartzen bere esanahiaren barnean (25). Aditz beraren beste erabilpen batek aldiz («metaforikoa» dei dezakeguna), erlazio eta kokapen aldaketa bati erreferentzia egin diezaioke (26), abiadura bizkorra zein indar batek eraginiko mugimendua oinarrian baititu (jaiduratasunaren lau ezaugarrietatik bi). Kanpoko agente baten indarrez jaurtikia den (26)ko entitate kokatuak (platerak), entitate kokatzailean (patioan) egin dezake, beraz, bere ibilbide osoa edo entite horretan buka dezake, ${ }^{12}$ hautatua den interpretazioaren arabera -kokapen aldaketa vs. erlazio eta kokapen aldaketa.

(25) L'oiseau a volé dans la cour 'Txoriak patioan hegaz/hegan egin $\mathrm{du}^{\prime}$

(26) L'assiette a volé dans la cour 'Platera patio-an/ra ziztuan ibili/joan da'

Orain arte azaldurikoarekin, argi dago kokapen aldaketazko aditz bat $\left(\mathrm{A}_{\mathrm{kkp-al}}\right)$ eta espaziozko PS bat (PS $\left.{ }_{\text {esp }}\right)$ elkartzen dituzten joskeren interpreta-

11 Gaur egun, PS bati josia den aller 'joan' aditzak erlazio eta kokapen aldaketa bat deskribatzen du batez ere (être 'izan' aditz laguntzailearekin doa). Antzinako frantsesean, aler predikatuak avoir 'edun' laguntzailearekin joateko zuen ahalmenak ((oinez) ibiltzea adierazten zuen aler-ek ; Nordahl 1977) artikulu honetan azterturiko joskera bertsuen aurrean garela erakustera ematen du. Alta bada, aller aditzak ez du jaiduratasunak biltzen dituen ezaugarrietatik bakar bat ere islatzen. Bere eduki semantiko orokorrak «aditz arin» ('light verb'; 'verbe support' edo «euskarri aditz» frantses hizkuntzalaritzaren terminologian) baten estatusa ematen diola dirudi eta horrek ditu, seguraski, erlazio eta kokapen aldaketazko joskerak ahalbidetzen, aditzari à preposizioa eransten zaionean partikulazki (aller à-k aditz lokuzio gisa funtzionatzen du kasik). Jaiduratasunetik at gelditzen den kasu hau franko berezia dugu beraz.

12 Kasu honetan gehitzen den erlazio aldaketa eraikitzerakoan, PSk adierazten duen konfigurazio mugiezkorra mugimenduaren bukaerako egoera bezala berrinterpretatzen da $(\neg \mathrm{r} \cdots \triangleright \mathrm{r})$. 
zioak eta hauei dagozkien egitura sintaktikoak bi elementu horien semantikak (batez ere aditzarenak) agintzen dituela. Kokapen aldaketa batetik erlazio eta kokapen aldaketarako bidea, bereziki, ez daiteke inolaz ere iragar alderdi semantikoak bazter batean utzirik. Formalizazio sintaktikoetan eratzen diren erregelek edo prozesuek beharko dute, horrenbestez, parametro anitz horiek islatu. $A_{\text {kkp-al }}+P_{\text {esp }}$ elementuez osatuak diren perpausak tratatzerakoan, aditzaren adierak jaiduratasunaren ezaugarrietako bat (bederen) dakarrenez egiaztatu beharko dute (erregelek/prozesuek) eta, denbora berean, PSk espazio preposizio mugiezkorra buru duela ziurtatu: ${ }^{13}$ baldintza horien pean soilik sortzen ahalko da erlazio eta kokapen aldaketak galdegiten duen egitura sintaktikoa, zeinetan PS aditzaren osagarria baita edo —erabilia den teoriaren arabera- A burutik hurbileko adjuntu bat (A'-ren adjuntua adibidez, X barra moduko errepresentazio batean) (Aurnague et al. 2001, Maienborn 1995). Kontrako kasuan (baldintzak ez badira betetzen), kokapen aldaketa hutsari doakion egitura eratuko da eta, aldi honetan, PS perpausaren modifikatzaile bat izanen da edo aditz sintagmaren (ASren) adjuntu bat (lehenago baino gorago dena ASren egituran, A burutik urrun(ago)).

Buka dezagun ikerketa honi loturik azken urteetan Tolosa Oktzitaniako (lehen mailako) zenbait eskolatan burutuak izan diren didaktika esperimentuak aipatuz. Zentzu hertsiko mugimendua adierazten duten edo adieraz dezaketen frantsesaren aditz eta joskera sorta erabilia izan da irakaskuntza esperimentu hauetan, besteak beste arakatu ditugun kokapen aldaketazko aditzak. Ikasleei proposatu zaizkien sailkatze ariketek (semasiologikoak) eta «errutinek» (ariketa onomasiologikoak) jaiduratasuna osatzen duten lau ezaugarrien berri dutela frogatu dute eta heien erabilpena ere menperatzen dutela (Aurnague \& Garcia-Debanc ebaluazioan). Halere, zenbait ñabardura agertu dira bi ariketa moten artean, eragiten dituzten prozesu kognitibo desberdinen ondorio izan daitezkeenak.

\footnotetext{
13 Preposizio edo preposizio sintagmen izaerari miatzeak badu bere inportantzia. De (Det) $I_{1} \grave{a}$ (Det) $I_{2}$ edo depuis/jusque (Det) I motako preposizio sintagmek, adibidez, ez dituzte egiazko erlazio eta aldaketa bat adierazten baizik eta distantzia baten neurketa. Erlazio eta kokapen aldaketazko deskribapenetan ez bezala (adib.: ??Max a marché au rocher 'Max harkaitzera ibili da', Max a couru au rocher 'Maxek harkaitzera laster egin $\mathrm{du}^{\prime}$ ), kokapen aldaketazko predikatu guztiek dituzte distantziazko PS horiek onartzen (adib.: Max a marché de l'arbre au rocher 'Max zuhaitzetik harkaitzera ibili da'; Max a marché jusqu'au rocher 'Max harkaitzeraino ibili da'; Max a couru de l'arbre au rocher 'Maxek zuhaitzetik harkaitzera laster egin du'; Max a couru jusqu'au rocher 'Maxek harkaitzera laster egin du'). Bestalde, Max a couru de la maison au village 'Maxek etxetik herrira laster egin $\mathrm{du}^{\prime}$ /Max a couru jusqu'au village 'Maxek herriraino laster egin du' bezalako perpausek ez dute Max a couru au village 'Maxek herrira laster egin du' esaldiaren edukia inplikatzen (cf. Aurnague 2012). Arrazoi horiengatik guztiengatik, distantziazko PSek ez dutela «zuzenean» erlazio eta kokapen aldaketarik aipatzen uste dugu (kokapen aldaketa neurtuak besterik ez dira) eta, hortaz, egituran duten funtzio sintaktikoak ez luke aditzaren osagarri batena izan behar.
} 


\section{Erreferentzia bibliografikoak}

ANDERSSON, C. (2007), Equivalence et saillance dans l'expression de la localisation frontale dynamique en suédois et en français : étude comparative et contrastive de fram et de ( $\left.\mathrm{s}^{\prime}\right)$ avancer/en avant. Uppsala: Uppsala University.

Aurnague, M. (2011), «How motion verbs are spatial: the spatial foundations of intransitive motion verbs in French». Lingvisticae Investigationes 34:1: 1-34.

Aurnague, M. (2012), «De l'espace à l'aspect : les bases ontologiques des procès de déplacement». Corela, zenbaki tematikoa (Langue, espace, cognition, B. Fagard \& D. Stosic (arg.)), http://corela.edel.univ-poitiers.fr/index.php?id=2846

Aurnague, M. (osatzekoa), «Strict autonomous motion in French: elements of semantic modelling».

Aurnague, M., Bras, M., Vieu, L. \& Asher, N. (2001), «The syntax and semantics of locating adverbials». Cahiers de Grammaire 26: 11-35.

Aurnague, M. \& Garcia-Debanc, C. (ebaluazioan), «Les verbes de déplacement comme contenu d'enseignement du lexique à l'école primaire : modélisation sémantique et analyse de productions d'élèves».

Aurnague, M. \& VIeU, L. (2015), «Function vs. regions in spatial language: a fundamental distinction». In C. Astésano \& M. Jucla (arg.), Neuropsycholinguistic perspectives on language cognition. Essays in honour of Jean-Luc Nespoulous. Londres/New York: Psychology Press, 31-45.

Boons, J.P. (1987), «La notion sémantique de déplacement dans une classification syntaxique des verbes locatifs». Langue Française 76: 5-40.

DinI, L. \& Di TOMASO, V. (1999), «Linking theory and lexical ambiguity: the case of Italian motion verbs». In H. Bunt \& R. Muskens (arg.), Computing meaning (1. liburukia). Dordrecht: Kluwer, 321-337.

Fong, V. \& Poulin, C. (1998), «Locating linguistic variation in semantic templates». In J.P. Koenig (arg.), Discourse and cognition: bridging the gap. Stanford, CA: CSLI, 29-39.

JaCKendoff, R. (1983), Semantic and cognition. Cambridge, MA: MIT Press.

JACKENDOFF, R. (1990), Semantic structures. Cambridge, MA: MIT Press.

KорескA, A. (2009), «L'expression du déplacement en français : l'interaction des facteurs sémantiques, aspectuels et pragmatiques dans la construction du sens spatial». Langages 173: 54-75.

KrIFKA, M. (1995), «Telicity in movement». In P. Amsili, M. Borillo \& L. Vieu (arg.), Time, Space and Movement: meaning and knowledge in the sensible world, Working Notes of the $5^{\text {th }}$ International Workshop. Tolosa-Toulouse: LRC, 63-75 (Part A).

LaUr, D. (1991), Sémantique du déplacement et de la localisation en français : une étude des verbes, des prépositions et de leurs relations dans la phrase simple. Doktorego tesia, Université de Toulouse-Le Mirail.

Levin, B. (1993), English verb classes and alternations: a preliminary investigation. Chicago: The University of Chicago Press.

LeVIN, B. \& RAPPAPORT, M. (1992), «The lexical semantics of verbs of motion: the perspective from unaccusativity». In I.M. Roca (arg.), The thematic structure: its role in grammar. Berlin: Foris Publications, 247-269.

LEVIN, B. \& RAPPAPORT, M. (1995), Unaccusativity: at the syntax-lexical semantics interface. Cambridge, MA: MIT Press. 
MaIENboRn, C. (1995), «Toward a Compositional Semantics for Locative Modifiers». In Proceedings from Semantics and Linguistic Theory V. Ithaca, NY: Cornell University Linguistic Publications, 237-254.

NordaHL, H. (1977), «Assez avez alé : estre et avoir comme auxiliaires du verbe aler en ancien français». Revue Romane XII-1: 54-67.

RANDALL, J.H. (2010), Linking: the geometry of argument structure. Dordrecht: Springer.

SARDA, L. (1999), Contribution à l'étude de la sémantique de l'espace et du temps : analyse des verbes de déplacement transitifs directs du français. Doktorego tesia, Université de Toulouse-Le Mirail.

SLobin, D.I. (2003), «Language and thought online: cognitive consequences of linguistic relativity». In D. Gentner \& S. Goldin-Meadow (arg.), Language in mind: advances in the investigation of language and thought. Cambridge, MA: MIT Press, 157191.

SLobIN, D.I. (2004), «The many ways to search for a frog: linguistic typology and the expression of motion events». In S. Strömqvist \& L. Verhoeven (arg.), Relating events in narrative: typological and contextual perspectives. Mahwah, NJ: Lawrence Erlbaum, 219-257.

TALMY, L. (1985), «Lexicalization patterns: semantic structure in lexical forms». In T. Shopen (arg.), Language typology and syntactic description (3. liburukia): grammatical categories and the lexicon. Cambridge: Cambridge University Press, 57-143.

TALMY, L. (2000), Toward a cognitive semantics (1. \& 2. liburukiak). Cambridge, MA: MIT Press.

TENNY, C. (1995), «How motion verbs are special: the interaction of linguistic and pragmatic information in aspectual verb meanings». Pragmatics and Cognition 3-1: 31-73.

VANDeloise, C. (1986), L'espace en français : sémantique des prépositions spatiales. Paris: Seuil.

VAndeloise, C. (2008). «Three basic prepositions in French and in English: a comparison». Carnets de Grammaire 19. Tolosa-Toulouse: CLLE-ERSS txostena.

Vendler, C. (1957), «Verbs and times». Philosophical Review 66: 143-160.

Wittgenstein, L. (1953), Philosophical investigations. New York: The Mc Millan Co. 


\section{Xabierri}

TIGES

Un peuplier sous les étoiles

Que peut-il.

Et l'oiseau dans le peuplier

Rêvant, la tête sous l'exil

Tout proche et lointain de ses ailes,

Que peuvent-ils tous les deux

Dans leur alliance confuse

De feuillages et de plumes

Pour gauchir la destinée.

Le silence les protège

Et le cercle de l'oubli

Jusqu'au moment où se lèvent

Le soleil, les souvenirs.

Alors l'oiseau de son bec

Coupe en lui le fil du songe

Et l'arbre déroule l'ombre

Qui va le garder tout le jour.

Jules Supervielle, Gravitations, 1925

\section{ZURTOIN(AK)}

Zurzuri batek izarren azpian

Zer diro.

Eta txoria zurzurian

Ameslari, burua hegaletako desterru

Pean hur-hurrean bezain urrun,

Zer dirote biek

Hostail eta lumazko

Batasun lausoan

Halabeharraren behartzeko.

Isiltasunak ditu gerizatzen

Eta ahanzturaren zirkuluak

Eguzkia eta oroitzapenak

I(r)atzartzen diren arte.

Orduan du txoriak mokoz

Ebakitzen bere baitako ametsaren haria

Eta zuhaitzak hedatzen

Egun-argi osoko itzal zaindaria.

M.A.k euskaratua 